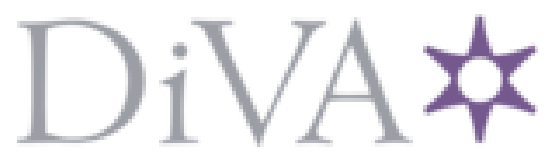

http://www.diva-portal.org

\title{
Postprint
}

This is the accepted version of a paper published in Metaphilosophy. This paper has been peer-reviewed but does not include the final publisher proof-corrections or journal pagination.

Citation for the original published paper (version of record):

Brunnander, B. (2011)

Philosophy and default descriptivism: The functions debate.

Metaphilosophy, 42(4): 417-430

http://dx.doi.org/10.1111/j.1467-9973.2011.01701.x

Access to the published version may require subscription.

N.B. When citing this work, cite the original published paper.

Permanent link to this version:

http://urn.kb.se/resolve?urn=urn:nbn:se:su:diva-63254 


\section{PHILOSOPHY AND DEFAULT DESCRIPTIVISM: THE FUNCTIONS DEBATE}

Abstract: By focusing on contributions to the literature on function ascription, this article seeks to illustrate two problems with philosophical accounts that are presented as having descriptive aims. There is a motivational problem in that there is frequently no good reason why descriptive aims should be important, and there is a methodological problem in that the methods employed frequently fail to match the task description. This suggests that the task description as such may be the result of "default descriptivism," a tendency to take considerations that make sense of a practice to be the very considerations that generate it. Although such hypotheses are frequently quite plausible, the fact of the matter may not be very important for the pursuits of philosophers.

Key Words: description, empirical data, explication, function, method, task description.

\section{Introduction.}

During the past four decades or so analyses of 'function' and related seemingly teleological notions have formed a prominent part of the philosophy of biology. No analysis is as of yet beyond controversy. But apart from diverging opinions about how to construe 'function' it has become evident that there is some controversy about what kind of intellectual task an analysis of 'function' is or should be (Millikan 1989, Neander 1991a, Amundson and Lauder 1994, Mitchell 1995/1998, Schwartz 2004). Are philosophers to discover on which grounds function ascription is actually performed, are they to explain why the practice has utility, or is it sufficient if they "merely" provide a useful standard for future use? 
This question concerning philosophy's descriptive credentials will clearly be quite familiar to those acquainted with the ongoing debate about conceptual analysis (Bishop 1992, DePaul and Ramsey 1998, Jackson 1998, Miller 2000, Stich and Weinberg 2001, Laurence and Margolis 2003, Sandin 2005. Lewens 2004, and Schwartz 2004, address the functions debate specifically). Now, there are indeed many strands in that debate, but one deals with philosophy's credentials as a descriptive enterprise. Focusing on the functions debate, I will point to two problems regarding philosophy and description. First, there is frequently no clear motivation why self-professed "descriptivists" should saddle themselves with descriptive commitments. Secondly, the methods used are frequently inappropriate given that the descriptive commitments are to be taken seriously.

Neither claim is original per se. This work clearly elaborates on themes that have been voiced by others (Brown 1999, Schwartz 2004). Its claim to originality lies, except for the rather detailed case study it provides, in the way questions of motivation and questions of method, together with some empirical background, are combined to argue that the functions debate exhibits a tendency to, mistakenly, present the task as aiming to be descriptively correct about existing conceptions. This is what I call default descriptivism. Although the general case is not here argued for, I suggest that we are well advised to be alert to default descriptivism in philosophical debates generally.

\section{The Motivational Issue.}

Quite a few contributions to the functions debate aim, as gathered from explicit task descriptions, at a descriptively correct account of 'function'. Here is a sample of philosophers who could reasonably be taken to announce a descriptive 
perspective within this field: Mark Bedau aims to uncover the role of value notions underlying our use of prima facie teleological terms $(1992 / 1998,286)$, Christopher Boorse presents $17^{\text {th }}$ century anatomist William Harvey as a counterexample to a selectionist analysis i of 'function' on the grounds that Harvey could not have had selection in mind when he attributed a function to the heart (1976, 74), Peter Godfrey-Smith aims to capture an existing concept and the role it plays in biology $(1994,200)$, Valerie Gray Hardcastle wants an answer to a question like "Why do we say that legs are for walking and not for balancing?" (2002, 146), Sandra Mitchell speaks of elucidating the intended explanatory role of function ascription $(1995 / 1999,397)$, Karen Neander presents her account as “...an attempt to understand what goes on inside speakers' heads..." (1991a, 170171), Lowell Nissen endorses an intentionality account of 'function' and related terms partly because he takes it to explain enduring controversy surrounding such language (1997, 227-228), and Larry Wright is looking for what we actually mean by 'function' (1973/1999, 33). Whatever the differences between the accounts they all seemingly endorse the idea that the project is one of discovery; the reported aim is to disclose features that shape prevailing practice.

However, if one looks at standard accounts of the rationale for the philosophical interest in 'function' and related notions it is far from obvious that what we need is description of prevailing conceptions. It is commonly agreed that the interest in such notions have been much driven by perceived problems. The philosophical problem is frequently presented as arising from the suspicion that the use of seemingly teleological terms in biology is a mere remnant of a superseeded worldview (Buller 1999, Perlman 2004). A quite common characterisation of the interest in 'function' is that the term is rather unproblematic if we can 
assume that the items at hand are products of intelligent creatures, but that it is much harder to make sense of it in a realm where intentions are precluded. So, for instance, Mark Perlman writes $(2004,4)$ : "It is easy to see how artifacts produced by humans would have functions, derived from the intentions of the human designers, but without God it seemed impossible to believe that teleology has a place in Nature." Similar remarks are made by Neander (1991b, 456- 457), Mitchell (1995/1998, 398), Buller (1999, 3), and Cameron $(2004,73)$.

Now, in order to ensure ourselves that it is quite safe to use 'function' and related notions in biology it appears to be sufficient if we are able to provide a theoretically decent definition for future use. It cannot be overwhelmingly important whether this was what we, or at least the biologists, meant all along. Thus, as Peter Schwartz notes in addressing Karen Neander's approach (Schwartz 2004), it seems that we could settle for philosophical explication in Quine's sense. As Quine saw it, this enterprise aims at providing an explicit standard that solves perceived problems surrounding a notion without purporting to describe what the relevant speakers had in mind all along (Quine 1961, 258). ${ }^{\text {ii }}$

This is not saying that what is proposed in explications cannot be descriptively correct also. It is certainly quite legitimate for philosophers to hypothesise that they are on to something descriptively correct. However, it is not clear why the fact of the matter should be important for their work qua philosophers.

In this context it may be illuminating to consider evolutionary biologist George C. Williams' approach to teleological language in biology, as presented in his influential book Adaptation and Natural Selection. This book was partly motivated by the author's dissatisfaction with how 'function' and related terms 
were used by quite distinguished fellow biologists. Williams writes $(1966 / 1996$, 8-9):

In many published discussions it is not at all clear whether an author regards a particular effect as the specific function of the causal mechanism or merely as an incidental consequence. In some cases it would appear that he has not appreciated the importance of the distinction. In this book I will adhere to a terminological convention that may help to reduce this difficulty.

Mostly the trouble in communication Williams noted was ambiguity, but perhaps sometimes sheer mysteriousness. The feeding activities of earthworms provide a good example of ambiguity (Williams 1966/1996, 18-19). A lot of other creatures may benefit from the work earthworms perform in the soil. A claim that such benefits for whole ecological systems constitute the function of the activity could be interpreted in at least two ways. On one interpretation the claim is simply that once there are, for whatever reasons, "digging" earthworms, a lot of other lineages will be adjusted to utilise whatever beneficial effects this brings. Then, earthworms may come to play a significant causal role on a grand ecological scale. On Williams' recommendation function ascription would instead require that the beneficial effects on mention somehow feed back to benefit "digging" earthworms over "non-digging" ones. That is, on this reading 'function' should be used only to convey a selectionist account of the proliferation and/or maintenance of the focal trait. 
So, Williams's problem was that it was frequently impossible to tell which hypothesis was being offered by the use of 'function'. And, reading his examples, there is reason to think that the users of the language were not always clear about this themselves. ${ }^{\text {ii }}$

It is rather obvious that Williams didn't need to be descriptively accurate about actual function ascription in order to solve his problem. He needed an explicit standard that, if heeded, would provide a reasonable and univocal interpretation among biologists. Williams did hold that his reading of 'function' was already employed (citing Muller 1948, Pittendrigh 1958, and Simpson 1963, as predecessors), but presumably did not take its mere occurrence to support his position. After all, the problematic interpretations he criticised were also in use, and I can't imagine that he would have been much impressed by attempts to hold this fact alone against him.

Given that we accept that one may indeed do useful work on an intellectual tool without purporting to be descriptively correct, we need an account of why description should matter more for philosophers interested in 'function' than it did for Williams.

I assume that philosophers' interest in attempting an explanatory account of some term's range of application is frequently linked to the belief that the minds at issue have tracked something significant in applying the term. It shouldn't be controversial that our minds manage a lot of information processing that is beyond introspective report. It is perhaps not very daring to assume that preconscious processing sometimes carve nature at the right places without us realising that. Thus, pre-theoretical practice may sometimes be sensitive to distinctions and variables that, if only brought out in the open, would contribute to our theoretical 
account of the world. It seems that some philosophers opt for the optimistic position of taking this to be the general expectation. So for instance, Frank Jackson holds that we typically "...know something useful and non-gruelike, and are giving voice to this knowledge when we classify happenings as examples of grooming behavior, pain, rational inference, and so on." (Jackson 1998, 64-65). Still, however plausible this may seem, we need to be told why it matters whether the account we present, assuming it to be theoretically fruitful, is descriptively correct also.

\subsection{Default Descriptivism.}

One may suspect that the descriptive commitments of philosophers involved in the functions debate are frequently taken on board unnecessarily. There is some evidence, well known to philosophers in various fields, that we are spontaneously inclined towards "default descriptivism". Experimental results involving split brain patients (Gazzaniga et al 1977, Gazzaniga 1998) and ordinary people (Nisbett and Wilson 1977) suggest that we, when cognitive causation is not conspicuous, are likely to refer to information that is not utilised by a cognitive mechanism generating a response as causally efficacious if it appears to make "good sense" of the response. We tend by default to believe that information that makes for rationalisation also provides causal explanation. It could be claimed here that these results have no clear bearing on my case as they deal with subjects rationalising their own specific responses rather than with the rationalisation of widespread practices. However, I don't think it far-fetched to assume that the tendency concerning one's own responses is likely to spread to widely occurring 
practices to the extent the latter conform to the former, which condition I think holds in the cases discussed here.

A quite plausible contemporary picture of the human condition is that rather versatile cognitive mechanisms frequently find themselves facing outputs from other mechanisms whose mode of operation is largely invisible. This means that the causal pathways responsible for the output are simply not there to be detected introspectively, but the relation between the output and our best theories may be open to investigation. So, the "sophisticated" mechanisms do what they can do under the circumstances, which is to interpret the output in terms of the information available to them. If they manage to produce a fit they have us conclude by default that this is the causal account (Bisiach and Geminiani 1991, Gazzaniga et al 1977, Rolls 1999, see Hirstein 2005, esp. ch. 7, for a review). If this is a common human predicament philosophers are not likely to be immune. So, we may well be inclined to presuppose that if we have succeeded in making sense of a practice we have thereby uncovered the very content that generates it. Not that this is a far-fetched hypothesis, but it isn't established by mere presupposition. More importantly, if our aim is to improve the practice it may not matter whether it is true or not.

Harold Brown (1999, 51-52) shares this suspicion that philosophers sometimes misdescribe prescriptive enterprises as descriptive ones, citing Wilfrid Sellars who once spoke of philosophers who confuse their "...creative enrichment of the framework of empirical knowledge, with an analysis of knowledge as it was." (Sellars 1963, 195). 


\subsection{Ways in Which Description Matters.}

There are, no doubt, reasons why descriptive accuracy regarding actual practice sometimes should matter for philosophers. One good motivation is a desire to investigate whether intuitions actually are as philosophers say they are. This certainly requires an empirically-minded interest in what conceptions people actually have, and is illustrated by the work of Stotz et al. (2004) on how biologists think about genes, Machery et al. (2004) on reference, and Weinberg et al. (2001) on knowledge. A slightly different route to taking descriptive aims on board is that one may suspect that some widespread linguistic practice in fact doesn't carve nature at significant places, although there is some utility to it. People who doubt the profound importance of some pre-theoretical extension may find themselves compelled to explain away its perceived significance, or at least show it to be based on relatively superficial merits. It would seem that such an enterprise would require hypotheses about which cues and variables minds are sensitive to in applying the notion at hand. Within the functions debate contributions from Ruse (2002) and Lewens (2004) are in this vein. These authors invoke analogy based on appearance between artefacts and biological traits in their attempts to account for the employment of teleological terms. They regard the use of such terms within biology as having heuristic value, but show no concern for questions about their exact range of application. So, for instance, Michael Ruse wouldn't mind the use of 'function' about inorganic processes that happened to be design-like in appearance $(2002,42)$.

So, I am not claiming that philosophers never have reason to care about descriptive accuracy regarding prevailing conceptions. What I am claiming is that quite a few self-proclaimed descriptivists fail to motivate their task description. 


\section{The Methodological Issue.}

Once we bring descriptive commitments into our task description things cannot but change from a methodological point of view. A contribution that is excellent qua explicit standard for future use may nevertheless be mistaken and/or methodologically flawed qua descriptive account. That much ought to be quite unsurprising. But then, what should we demand of accounts that purport to aim at descriptive accuracy?

\subsection{On the Non-use of Polling.}

A quite general worry about the descriptive aspects of conceptual analysis is that such aims seem to render empirical investigation of prevailing intuitions highly relevant, methods that are not much in use, however (Brown 1999, Stich and Weinberg 2001, Schwartz 2004, Stotz et al. 2004). The method employed by selfproclaimed descriptivists in the functions debate is typically not asking members of the relevant crowd what they're doing. Again, in some areas philosophers have recently partaken in such empirical investigations, but I have not encountered anything of the kind in the literature on function.

One is left to speculate about this seeming methodological omission since it isn't, as far as I know, explicitly defended. In his general defence of conceptual analysis, Frank Jackson claims that while the method of polling should be used when necessary, we frequently can tell whether intuitions are representative or not (Jackson 1998, 36). Now, I agree with Brown (1999) and Stich and Weinberg (2001) that there is reason to question this view. As will be illustrated below, one 
is entitled to suggest that we are somewhat near-sighted when it comes to detecting evidence for intuitions we don't approve of.

One may presumably be granted the right not to poll the relevant crowd if it can be assumed that the grounds for ascription are not introspectively conspicuous. However, I would think that scientists are frequently reliable sources as to what accounts for their application of various notions. At least, it would seem a bit quick to merely presuppose that it's no use asking them. Given this, it is unclear why the method of gathering self-reports from the relevant practitioners is absent from the repertoire of philosophers who claim to attempt to elucidate function ascription. Karen Neander (1991a) can serve to illustrate this:

An argument that has been raised against selectionist accounts of 'function' is that 17 th century anatomist William Harvey couldn't possibly have had selection in mind when ascribing a function to the heart (Boorse 1976, Nagel 1977, Enç 1979). Neander claims that this argument is unproblematic for her selectionist account since her target is criteria of ascription among current biologists, and they may differ from Harvey in relevant ways (1991a, 176). Well, perhaps they do. However, for all we know current biologists may rather frequently ascribe functions utilising the same causal mechanisms as Harvey did. To strengthen the case for there being a difference between current biologists and Harvey, Neander says that it is a commonplace that “...scientific terms are shaped by background theories.” (1991a, 176). This is a plausible assumption as regards 'function'. Selectionist accounts have, according to Williams (1966), been proposed among biologists for quite some time and has presumably had some impact on biological practice. But now there is at least a prima facie tension in Neander's approach. One the one hand she avoids the threat from Harvey by claiming that current 
function ascription among biologists is shaped by evolutionary theory. On the other hand, on reflecting on the methods she employs it seems that she takes this shaping to be insufficiently clear to the theorists themselves. Neander remarks: "Of course I do not claim that modern biologists have natural selection consciously or explicitly in mind when they use the notion of a "proper function". If that were required, conceptual analysis could be done by deed poll" (1991a, 176). She provides no reasons for supposing that such a method wouldn't work in the case of biologists and 'function', a case in which she suggests that actual usage is shaped by an explicit theory.

Now, as indicated above, there are well-known quite general doubts concerning the reliability of self-reports. One may of course ask whether such doubts are equally plausible on the assumption, made by Neander, that the practice to be explained is shaped by scientific theory. Still, let's grant that there is always some risk of self-reports being unreliable. Then, we should look at what subjects do rather than what they say about what they do. In the current case, we should look at how biologists actually ascribe functions rather than at what they say about function ascription. However, the descriptive enterprise does not really deliver in this respect either; there are frequent indications in the literature on 'function' that unfit data are simply disregarded or, perhaps more commonly, that no serious effort is made to find out whether there is indeed such data.

\subsection{Laxity about Empirical Data.}

a. Karen Neander compares the merits of her selectionist account of 'function' with the propensity account of Bigelow and Pargetter (1987). Bigelow and Pargetter argue for a "forward-looking" account that allows $1^{\text {st }}$ generation token 
traits to be ascribed functions. On Neander's historical account, on the other hand, an effect may be a function only if there has been selection for that very effect. To point to the superiority of her theory Neander states (1991b, 465): “According to current usage, a new mutation has no function." She clearly takes this to provide good support for her theory. Neander doesn’t provide any further information or any references to support her claim about current usage. So, perhaps she takes it to be just dead obvious that biological practice is what she claims it is. However, Peter Godfrey-Smith claims, providing two references, that forward-looking accounts may find some support in that "...it is common for writers to both regard functions as ahistorical and regard them as intrinsically tied to natural selection...", (1994, 208, emphasis is original). The issue here is not what we believe that a study of biological practice would reveal, it is methodological: Neander doesn't perform in a way that we are entitled to expect from someone who claims to be proposing a theory about what goes on in the minds of biologists when they ascribe function.

$b$. An oft-cited counter-example to selectionist accounts of 'function' concerns segregation distorter genes (Godfrey-Smith 1994, Manning 1997, Boorse 2002). Segregation distorters impair the formation of sex-cells (meiosis) inhabited by alternative genes that are "competing" for the same location in the genome (Crow 1979). This effect clearly seems to be something that accounts for proliferation (of the distorters, that is) so it ought to count as a function on a selectionist view. Several authors have claimed that biologists do not use 'function' in such cases: "Disrupting meiosis is not generally claimed to be the genes' function..." (Godfrey-Smith 1994, 204, emphasis is original). 
Now, reading accounts that invoke segregation distorters as a counterexample in the functions debate, and do so on descriptive grounds (such as Godfrey-Smith 1994, Manning 1997, Boorse 2002, and Hardcastle 2002), one looks in vain for empirical support or any references relevant for evaluating the crucial claim regarding biological practice. But if the contribution's claim to fame is supposed to rely on descriptive accuracy then unsupported statements about what biologists do or think look a bit meagre. At least, it doesn't strike me as at all obvious what the result would be of actually polling biologists on this one, and Godfrey-Smith himself suggests that some biologists might actually be inclined to disagree with his verdict $(1994,205)$. If there is indeed a minority with deviant intuitions it is far from clear how theorists with self-proclaimed descriptive aims could be entitled to disregard them (as noted by Brown 1999, in assessing Frank Jackson's general account of conceptual analysis).

Richard Manning claims that to propose a definition of 'function' that allows ascription of function to segregation distorters "... would be to dictate the content of science from the philosopher's armchair." $(1997,76)$. It has yet to be shown that the unanimous answer Manning suggests would be forthcoming from biologists on this issue would in fact do so. It seems to me that he, along with some other colleagues, doesn't mind dictating the content of scientists' heads from the philosopher's armchair. Again, my point is methodological. If our accounts are to depend on claims regarding actual scientific practice we should be sensitive to the empirical nature of the issue and acknowledge the risk of merely projecting our own intuitions onto the targeted practitioners. 
c. Sandra Mitchell says she aims to uncover the intended content of 'function' in current science $(1995 / 1998,397)$. In defence of accounts that give a significant role to selection history, and against the forward-looking account of Bigelow and Pargetter (1987) on which functions may predate selection, she presents a case involving a "natural double". The Monarch butterfly and the Viceroy butterfly are, she claims, similar or even indistinguishable as for coloration $(1995 / 1998$, 405). The Monarchs are unpalatable and for that reason avoided once tasted. The Viceroys are palatable but benefit from looking like the Monarchs. The former species is the model and the latter the mimic, and although the beneficial effect is avoidance of predation in both cases the evolutionary histories are different. Mitchell asks (1995/1998, 405): "Do we want to say that the conspicuous coloration of the Monarch and Viceroy have the same function?" She immediately answers this question herself negatively. As for the Monarchs the function is “...to warn the predator of its unpalatability." As for the Viceroys it is rather “...to mimic the model and deceive the predator into presuming it is unpalatable and thereby avoid predation." $(1995 / 1998,405)$.

Now, given that Mitchell's aim is to uncover the intended role of 'function' in science it is puzzling that she employs the method of asking the readers, many of them philosophers, what they want to say about the test case she presents. It is also puzzling that she simply answers that question herself. It is hard to see how this procedure is to provide significant support as to what scientists in general intend when they ascribe functions. Relating what scientists in fact say would seem more to the point. To this end there is a quoted sentence from Wickler (1968) but although 'function' appears in it, it deals only with the application of the term 'mimicry'. iv 
d. Richard Cameron (2004) supports his belief that biological systems exhibit teleology by claiming that we need to trust our categorical intuitions on the matter. He must clearly be saying that seemingly teleological terms appear equally appropriate whether intentions are involved or not. Similarly, Mark Bedau insists that we need an explanation of "... why so many biological phenomena seem teleological." (1992/1998, 285, emphasis is original). There is no effort made in neither account to establish that the intuitions at issue are as widespread as suggested. It seems that the verdicts involved simply disregard the perceived inappropriateness some have felt regarding the use of 'function' and 'purpose' in non-mentalistic contexts, which sentiment is commonly held to have been a major motivation for analysing such terms (Allen et al. 1998, 1-2, Buller 1999, 6, Perlman 2004, 4). The situation is likely to be more complex psychologically than these thinkers assume. This point concerning problems with a firm trust in the significance of one's intuitions has been made several times before (Goldman 1992, 160, Hull 1998, 223-224, Brown 1999, 52, Lewens 2001, 183-184, Stich and Weinberg 2001, 640-643).

I submit that these examples illustrate a mismatch between task description and method. Something will have to change. Given the aforementioned lack of convincing reason to insist on descriptive accuracy I take it that, quite frequently, what is needed is really a revision of the task description.

\section{Concluding Remarks.}

It is clear that not all worthwhile philosophical projects demand being correct about what goes on inside the heads of folks or experts. Conceptual improvement 
is frequently the issue and, as illustrated by George C. Williams's (1966) account of 'function', then it seems not to be crucial whether a proposed definition is a true description of what the relevant crowd had in mind all along or not.

Although the general case has not been argued for here, I don't think that the functions debate is an outlier within philosophy when it comes to descriptive commitments. Much of what is said in the general debate about conceptual analysis indicate that it is rather frequently the case that authors purporting to pursue descriptive aims fail to provide a reasonable motivation for such an approach, and that the methods applied are insufficient given such a task. This provides scope for questioning the very accuracy of the task description as such. On encountering descriptive aims we should ask: Why is it important that the account is descriptively correct rather than that it "merely" presents a useful explicit standard for future practice? Would the author in fact consider his/her contribution a failure if it turned out that there was never a concept with the content he/she proposes, but that such a (novel) concept will make for improvement once it is presented?

I take the following methodological rule of thumb to be quite modest: We should refrain from burdening ourselves with the methodological demands that accompany descriptive hypotheses unless we can provide a good reason for thinking that descriptive accuracy is essential for the project. Philosophy should not be default descriptivism.

\section{Acknowledgements:}

I would like to thank Sören Häqqqvist and an anonymous referee for valuable comments on earlier drafts. 
Mailing address: Björn Brunnander, Department of Philosophy, Stockholm

University, 10691 Stockholm, Sweden

E-mail: bjorn.brunnander@philosophy.su.se 


\section{References:}

Allen, Colin, et al. 1998. Nature's Purposes: Analyses of Function and Design in Biology. Cambridge, MA, and London: MIT Press.

Amundson, Ron, and Lauder, George. 1994. "Function without Purpose: The

Uses of Causal Role Function in Evolutionary Biology." Biology and Philosophy 9: 443-469.

Bedau, Mark. 1991. “Can Biological Teleology be Naturalized?” Journal of Philosophy 88: 647-655.

Bedau, Mark. 1992/1998. "Where's the Good in Teleology? Philosophy and Phenomenological Research 52: 781-806. Reprinted in Nature's Purposes: Analyses of Function and Design in Biology, edited by Colin Allen et al. Cambridge, MA, and London: MIT Press.

Bigelow, John, and Pargetter, Robert. 1987. "Functions.” The Journal of Philosophy 84: 181-196.

Bishop, Maurice. 1992. "The Possibility of Conceptual Clarity in Philosophy.“ American Philosophical Quarterly 29: 267-277.

Bisiach, Edoardo, and Geminiani, Giuliano. 1991. “Anosognosia Related to Hemisplegia and Hemianopia.” In Awareness of Deficit after Brain Injury: Clinical and Theoretical Issues, edited by George Prigatano and Daniel Schachter, Oxford: Oxford University Press. 
Boorse, Cristopher. 1976. "Wright on Functions." Philosophical Review 85: 7086.

Boorse, Christopher. 2002. “A Rebuttal on Functions.” In Functions: New Essays in the Philosophy of Psychology and Biology, edited by André Ariew et al.

Oxford and New York: Oxford University Press.

Brown, Harold. 1999. "Why do Conceptual Analysts Disagree?" Metaphilosophy, 30: 33-59.

Buller, David. 1999. "Natural Teleology.” In Function, Selection, and Design, edited by David Buller, Albany: SUNY Press.

Cameron, Richard. 2004. "How to be a Realist about Sui Generis Teleology Yet Feel at Home in the 21st Century." The Monist, 87: 72-95.

Crow, James F. 1979. “Genes that Violate Mendel's Rules.” Scientific American, 240: $134-146$.

DePaul, Michael, and Ramsey, William. (Eds) 1998. Rethinking Intuition. Oxford: Rowman \& Littlefield.

Enç, Berent. 1979. "Function Attributions and Functional Explanations." Philosophy of Science 46: 343-365.

Gazzaniga, Michael. 1998. The Mind's Past. Berkeley: University of California Press.

Gazzaniga, Michael, et al. 1977. "Language, Praxis, and the Right Hemisphere:

Clues to some Mechanisms of Consciousness.” Neurology 27: 1144-1147.

Godfrey-Smith, Peter. 1994/1999. “A Modern History Theory of Functions.”

Nous 28: 344-362. Reprinted in Function, Selection, and Design, edited by David Buller. Albany: SUNY Press.

Goldman, Alvin. 1992. Liaisons. Cambridge, Mass: MIT Press. 
Hardcastle, Valerie. G. 2002. "On the Normativity of Functions.” In Functions: New Essays in the Philosophy of Psychology and Biology, edited by André Ariew et al. Oxford and New York: Oxford University Press.

Hirstein, William. 2005. Brain Fiction. Cambridge, MA, and London: MIT Press. Hull, David. 1998. "Introduction to Part IV." In The Philosophy of Biology, edited by David Hull and Michael Ruse. Oxford and New York: Oxford University Press.

Jackson, Frank. 1998. From Metaphysics to Ethics. Oxford: Oxford University Press.

Kitcher, Philip. 1993/1998. "Function and Design”. Midwest Studies in Philosophy 18: 379-397. Reprinted in Nature's Purposes: Analyses of Function and Design in Biology, edited by Colin Allen et al. Cambridge, MA, and London: MIT Press.

Laurence, Stephen, and Margolis, Eric. 2003. "Concepts and Conceptual Analysis." Philosophy and Phenomenological Research 67: 2, 253-282. Lewens, Tim. 2001. "No End to Function Talk in Biology." Studies in History and Philosophy of Biological and Biomedical Sciences 32: 179-190.

Lewens, Tim. 2004. Organisms and Artifacts. Cambridge, MA, and London: Bradford.

Lorenz, Konrad. 1963. On Aggression. London: Methuen.

Machery, Edouard, et al. 2004. "Semantics, Cross-Cultural Style.” Cognition 92: B1-B12.

Manning, Richard. 1997. "Biological function, Selection, and Reduction.” British Journal for the Philosophy of Science 48: 69-82.

Miller, Richard. 2000. "Without Intuitions". Metaphilosophy 31: 231-250. 
Millikan, Ruth G. 1989. “In Defense of Proper Functions.” Philosophy of Science 56: $288-302$.

Mitchell, Sandra. 1995/1998. "Function, Fitness and Disposition.” Biology and Philosophy 10: 39-54. Reprinted in Nature's Purposes: Analyses of Function and Design in Biology, edited by Colin Allen et al. Cambridge, MA, and London: MIT Press.

Muller, Hermann J. 1948. "Evidence of the Precision of Genetic Adaptation." Harvey Lectures 43: 165-229.

Nagel, Ernest. 1977. “Teleology Revisited”. Journal of Philosophy 74: 261-301. Neander, Karen. 1991a. "Functions as Selected Effects: The Conceptual Analyst's Defence." Philosophy of Science 58: 168-184.

Neander, Karen. 1991b. “The Teleological Notion of Function.” Australasian Journal of Philosophy 69: 454-468

Nisbett, Richard, and Wilson, Timothy. 1977. "Telling More than We can Know: Verbal Reports on Mental Processes.” Psychological Review 84: 231-259.

Nissen, Lowell. 1997. Teleological Language in the Life Sciences. Lanham and Oxford: Rowman \& Littlefield.

Perlman, Mark. 2004. "The Modern Resurrection of Teleology." The Monist 87: $3-51$.

Pittendrigh, Colin. 1958. “Adaptation, Natural Selection, and Behavior.” In Behavior and Evolution, edited by Anne Roe and George G. Simpson. Yale University Press.

Quine, Willard. V. O. 1961. Word and Object. Cambridge, MA: MIT Press. Rolls, Edmund T. 1999. The Brain and Emotion. Oxford: Oxford University Press. 
Ruse, Michael. 2002. "Evolutionary Biology and Teleological Thinking." In Functions: New Essays in the Philosophy of Psychology and Biology, edited by André Ariew et al. Oxford and New York: Oxford University Press.

Sandin, Per. 2006. "Has Psychology Debunked Conceptual Analysis?”

Metaphilosophy 37: 26-33.

Schwartz, Peter. 2004. "An Alternative to Conceptual Analysis in the Function Debate." The Monist 87:136-153.

Sellars, Wilfrid. 1963. Science, Perception and Reality. New York: Humanities Press.

Simpson, George. G. 1962. "Biology and the Nature of Life." Science 139: 81-88.

Stich, Stephen, and Weinberg, Jonathan. 2001) "Jackson's Empirical Assumptions." Philosophy and Phenomenological Research 62: 637- 643.

Stotz, Karola, et al. 2004. "How Biologists Conceptualise Genes: An Empirical Study." Studies in History and Philosophy of Biological and Biomedical Sciences 35: 647-673.

Weinberg, Jonathan, et al. 2001. "Normativity and Epistemic Intuitions." Philosophical Topics 29: 429-460.

Wickler, Wolfgang. 1968. Mimicry in Plants and Animals. McGraw Hill.

Williams, George.C. 1966/1996. Adaptation and Natural Selection. Princeton:

Princeton University Press.

Wright, Larry. 1973/1999. "Functions.” Philosophical Review 82: 139-168.

Reprinted in Function, Selection, and Design, edited by David Buller. Albany: SUNY Press. 


\begin{abstract}
Notes
${ }^{\mathrm{i}}$ Roughly, such an analysis claims that something is a function only if it is an effect that accounts for the selective advantage of the structure that produces the effect.
\end{abstract}

ii Trivially, if an explication is successfully implemented, and actually eliminates pre-theoretical ways of dealing with the explicated term, it will become a true account of what users have in mind.

iii One sometimes encounters the claim that philosophers of the recent past were overly sceptical about 'function' and similar notions. So, for instance, Mark Perlman finds it surprising that analytical philosophers "...would reject a notion that is so central to some areas of science, most notably biology and engineering sciences.” $(2004,4)$. Now, perhaps many philosophers reached their sceptical conclusions by flawed argumentation, but Williams' account provides ample evidence that the biological practice of the recent past wasn't entirely fit to give teleological notions a good reputation.

iv It reads: "In general, we use the term mimicry only when the mimetic characters have been evolved for a specific mimetic function.” (Wickler 1968, 108, quoted from Mitchell 1995/1999, 405). The quote seems to tell us that 'mimicry' is applied with an eye to the evolutionary past, but not that 'function' is. 
